\title{
MEJIRUNG: MESIN JERUJI SANGKAR BURUNG UNTUK MENINGKATKAN PRODUKTIVITAS PENGRAJIN SANGKAR BURUNG YANG TERDAMPAK PANDEMI COVID-19
}

\author{
Rahmat Hidayat $^{1}$, Rizki Achmad Darajatun ${ }^{2}$, Febi Kurniawan ${ }^{3}$, Supri Handoko ${ }^{4}$ \\ ${ }^{1)}$ Teknik Elektro, Fakultas Teknik, Universitas Singaperbangsa Karawang \\ ${ }^{2)}$ Teknik Industri, Fakultas Teknik, Universitas Singaperbangsa Karawang \\ ${ }^{3,4)}$ Pendidikan Jasmani, Kesehatan dan rekreasi, Fakultas Keguruan dan Ilmi Pendidikan, Universitas \\ Singaperbangsa Karawang \\ e-mail: rahmat.hidayat@staff.unsika.ac.id
}

\begin{abstract}
Abstrak
Permasalahan dari sisi penggunaan teknologi dalam pembentukan jeruji sangkar burung juga masih banyak Buruh pembentuk jeruji sangkar burung, Penjual sangkar burung serta Masyarakat Desa Jatimekar dan Mekargalih yang belum memanfaatkan teknologi modern sebagai alat bantu. Dengan adanya alat MEJIRUNG yang dibuat diharapkan proses membuat jeruji sangkar burung menjadi lebih mudah dan lebih aman serta mampu untuk meningkatkan produktivitas pengrajin sangkar burung yang terdampak pandemi Covid-19. Solusi dalam program ini adalah mendesiminasikan produk teknologi MEJIRUNG: Mesin Jeruji Sangkar Burung ke Masyarakat melalui: (a) pemanfaatan produk teknologi untuk masyarakat kelompok Pengrajin sangkar burung serta Masyarakat di Desa Jatimekar dan Mekargalih, Jatiluhur Purwakarta,(b) Pelatihan penggunaan teknologi, perawatan dan pembuatan MEJIRUNG, (c) peningkatan kemampuan SDM Pengrajin sangkar burung, serta Masyarakat dalam bidang teknologi. Hasil yang didapat kelompok sasaran atau mitra dari kegiatan Program produk teknologi yang di desiminasikan ke masyarakat dapat disimpulkan bahwa warga khususnya buruh pembuat jeruji sangkar burung dan pelaku UMKM Mebeller dapat mengetahui teori dan keterampilan dan penggunaan MEJIRUNG dengan baik dan benar. MEJIRUNG ini menurut buruh pembuat jeruju sangkar burung berdampak pada peningkatan kinerja karena MEJIRUNG dapat mempercepat proses pembuatan jeruji sangkar burung.
\end{abstract}

Kata Kunci : Desa Jatimekar dan Mekargalih, Mejirung, Pengrajin, Sangkar Burung

\begin{abstract}
Problems in terms of the use of technology in the formation of bird cage bars are also still a lot of workers forming bird cage bars, bird cage sellers and the people of Jatimekar and Mekargalih villages who have not used modern technology as a tool. With the MEJIRUNG tool made, it is hoped that the process of making bird cage bars will be easier and safer and able to increase the productivity of bird cage craftsmen who have been affected by the Covid-19 pandemic. The solution in this program is to disseminate MEJIRUNG technology products: Bird Cage Bars to the Community through: (a) the use of technology products for the community of bird cage craftsmen groups and communities in the villages of Jatimekar and Mekargalih, Jatiluhur Purwakarta, (b) Training on the use of technology, maintenance and making MEJIRUNG, (c) increasing the capacity of human resources for bird cage craftsmen, as well as the community in the field of technology. The results obtained by the target group or partners from the activities of the technology product program that are disseminated to the community can be concluded that residents, especially workers who make bird cage bars and Mebeller SMEs, can know the theory and skills and use of MEJIRUNG properly and correctly. MEJIRUNG, according to workers making bird cage bars, has an impact on improving performance because MEJIRUNG can speed up the process of making bird cage bars.
\end{abstract}

Keywords: Jatimekar and Mekargalih Village, Mejirung, Craftsmen, Bird Cage 


\section{PENDAHULUAN}

Mitra dalam program ini adalah Mitra dalam program ini adalah 1)Kelompok Pengrajin Sangkar Burung UMKM Mebeller "Danau Biru" Desa Jatimekar Kecamatan Jatiluhur Kabupaten Purwakarta, 2) Kelompok Pengrajin Sangkar Burung UMKM Mebeller "Esa" Desa Mekargalih Jatiluhur Purwakarta, 3) Bumdes Desa Jatimekar Kecamatan Jatiluhur Kabupaten Purwakarta, 4) Karangtaruna Desa Mekargalih Kecamatan Jatiluhur Kabupaten Purwakarta. Kelompok pengrajin sangkar burung yang sebagian besar adalah laki-laki. Seperti yang kita ketahui daerah Purwakarta merupakan salah satu daerah yang terkenal akan produk kerajinannya.

Salah satunya dalah Warga di Desa Jatimekar dan Mekargalih, Jatiluhur Purwakarta, yang sebagian besar pendapatan masyarakatnya adalah dari kerajinan sangkar burung, UMKM Mebeller dan buruh, Wiraswasta. Seperti yang kita ketahui bahwa pohon jati, dan bambu bertebaran di wilayah Purwakarta dan sekitarnya merupakan potensi yang besar sebagai bahan dasar kerajinan sangkar burung dan mebel, bahkan banyak orang yang menekuni kerajinan sangkar burung dan mebel. Sebagai contoh kelompok pengrajin sangkar burung, buruh dan penjual sangkar burung, pemilik UMKM Mebeller.

Kecamatan Jatiluhur berbatasan dengan kabupaten karawang di utara, kecamatan paswahan kabuapten purwakarta di selatan, Kecamatan Sukatani di barat dan Kecamatan Babakancikao dan kecamatan Purwakarta di timur. Kecamatan Jatiluhur terdiri dari delapan desa yaitu; (1) Jatimekar; (2) Mekargalih; (3) Jatiluhur; (4) Cilegong; (5) Kembangkuning; (6) Cibinong; (7) Parakanlima; (8) Cisalada; (9) Cikaobandung; (10) Bunder;. Desa Jatiluhur merupakan ibukota Kecamatan Jatiluhur yang memiliki luas $378 \mathrm{Ha}$, dengan jumlah padat penduduk sebesar 4.204 jiwa (BPS, 2019:8).

Pada saat sekarang ini peminat burung berkicau semakin marak. Mulai dari pelosok desa sampai ke perkotaan banyak orang memelihara burung berkicau. Lomba-lomba burung berkicaupun semakin sering diadakan sehingga memacu animo masyarakat untuk memelihara burung berkicau. Dalam memelihara burung berkicau tidak mungkin lepas dari penyediaan kandang atau sangkar burung. Sangkar burung yang beredar di pasaran kebanyakan terbuat dari kayu dan juga bambu, meskipun ada juga yang terbuat dari viberglass ataupun besi. Penggunaan kayu dan bambu untuk membuat sangkar burung lebih diminati karena adanya beberapa faktor diantaranya adalah kayu dan bambu mudah dibentuk dan dibuat lebih artistik atau mempunyai cita rasa seni yang tinggi.

Kerangka sangkar burung biasanya dibuat dari kayu jati atau pun jenis kayu lainnya yang memungkinkan untuk diukir. Sedangkan jerujinya biasanya menggunakan bambu yang diserut sehingga ukurannya dapat seragam dan mempunyai tingkat kehalusan yang cukup. Untuk memperoleh serutan jeruji sangkar burung yang sama ukurannya dan halus kebanyakan pengrajin sangkar burung mengerjakannya dengan cara manual yaitu dengan menyerut perlahan-lahan dengan pisau kecil yang tajam. Sedangkan untuk perusahaan sangkar burung yang lebih maju sedikit dengan menggunakan cetakan/mal yang kemudian ditarik dengan tangan dan menggunakan tenaga otot manusia. Tentu saja hal tersebut sangat memerlukan waktu yang lama dan melelahkan.

Dalam proses pembuatan sangkar burung mengalami beberapa permasalahan seperti pada proses pengupasan dan pembentukan pohon dan bambu menjadi jeruji sangkar burung, dimana sering kali terjadi kendala atau pun cidera ketika mengupas dan membentuk menjadi jeruji sangkar burung. Beberapa sektor mengalami beberapa permasalahan seperti pada proses pengupasan dan pembentukan sangkar burung dimana sering kali terjadi kendala atau pun cidera ketika membentuk jeruji sangkar burung dari bahan dasar kayu dan bambu. Dengan mengamati dan mempraktikkan sulitnya mengupas dan mebentuk jeruji sangkar burung secara konvensional maka penulis muncul keinginan untuk mendesiminasikan produk teknologi MEJIRUNG: Mesin Jeruji Sangkar Burung yang telah dibuat, yang dapat mempermudah melakukan proses pembuatan dan pembentukan jeruji sangkar burung. Dengan adanya alat yang dibuat diharapkan proses membuat dan membentuk jeruji sangkar burung menjadi lebih mudah dan lebih aman. Permasalahan dari sisi penggunaan teknologi dalam pembuatan dan pembentukan sangkar burung juga masih banyak Buruh serta Pengrajin pembuat sangkkar burung, Penjual Sangkar Burung serta Masyarakat Desa Desa Jatimekar dan Mekargalih, Jatiluhur Purwakarta yang belum memanfaatkan teknologi modern sebagai alat bantu. 
Berdasarkan pada uraian diatas maka pada program produk teknologi yang di desiminasikan ke Masyarakat ini akan mendesiminasikan alat tentang teknologi MEJIRUNG: Mesin Jeruji Sangkar Burung ke Masyarakat Mitra yang dapat mempermudah melakukan proses pengupasan dan pembentukan jeruji sangkar burung. Dalam proses pembuatan Jeruji Sangkar Burung hingga saat ini masih dilakukan secara manual di kalangan usaha menengah kebawah, dan proses tersebut juga membutuhkan waktu yang cukup lama, membutuhkan banyak tenaga, juga resiko/berbahaya karena biasanya menggunakan pisau dan golok yang tajam dalam membuat jeruji sangkar burung dan orang yang mengupas dan membentuk jeruji sangkar burung posisi badan dan tangannya memegang benda pisau dan golok tajam sehingga resiko cidera/terluka karena alat akan menjadi lebih besar.

Sehubungan dengan itu maka diperlukan alat/mesin yang dapat memperingan kerja pengrajin untuk mempermudah pembuatan jeruji sangkar burung yang berkualitas, yaitu yang memiliki hasil serutan yang halus dan ukurannya seragam. Selain itu, alat/mesin harus dapat memproduksi jeruji sangkar burung yang kapasitasnya lebih banyak dari cara pengerjaan manual sehingga dapat mempersingkat waktu pembuatan dan penghematan tenaga pengrajin sangkar burung.

Oleh sebab itu kami tertarik untuk mengatasi permasalahan pembuatan jeruji sangkar burung tersebut dengan Produk Teknologi yang di Desiminasikan ke Masyarakat tentang Mejirung: Mesin Jeruji Sangkar Burung Untuk Meningkatkan Produktivitas Pengrajin Sangkar Burung Yang Terdampak Pandemi Covid-19. Sehingga diharapkan pengrajin sangkar burung mampu memproduksi jeruji sangkar burung yang lebih banyak dan berkualitas dengan waktu yang lebih singkat dan menghemat tenaga pengrajin sangkar burung.

Dengan adanya MEJIRUNG: Mesin Jeruji Sangkar Burung yang dibuat diharapkan proses membentuk jeruji sangkar burung menjadi lebih mudah dan lebih aman serta mampu untuk meningkatkan produktivitas pengrajin sangkar burung yang terdampak pandemi covid-19. Permasalahan dari sisi penggunaan teknologi dalam pembentukan jeruji sangkar bururng juga masih banyak Buruh pengupas dan pembentuk jeruji sangkar bururng, Penjual sangkar burung serta Masyarakat Desa Jatimekar dan Mekargalih yang belum memanfaatkan teknologi modern sebagai alat bantu. Sampai saat ini belum ada alat bantu untuk membentuk jeruji sangkar burung yang dapat bekerja dengan aman dan efektif sehingga dengan segala keterpaksaan manusialah yang bekerja secara manual untuk membentuk jeruji sangkar burung dari bahan kayu dan bambu. Hal semacam ini di Indonesia merupakan hal yang lazim maka dibutuhkan MEJIRUNG: Mesin Jeruji Sangkar Burung dalam membantu pekerjaan dan meningkatkan produktivitas dari pengrajin sangkar burung.

Program produk teknologi yang di desiminasikan ke Masyarakat ini dimaksudkan untuk memberikan pemahaman, pelatihan, penggunaan dan perawatan produk teknologi kepada kelompok pengrajin sangkar burung, Buruh dan Penjual Sangkar Burung serta Masyarakat di Desa Jatimekar dan Mekargalih, Kecamatan Jatiluhur Kab. Purwakarta yang memiliki potensi dalam produk kerajinan bambu dan kayu yang sangat besar di wilayah ini. Sebagian besar Masyarakat Desa Jatimekar dan Mekargalih, Kecamatan Jatiluhur Kab. Purwakarta belum mengetahui kalau teknologi itu penting untuk membantu dan meringankan pekerjaan Buruh dan pengrajin sangkar burung, Penjual Sangkar Burung serta Masyarakat oleh karena itu diperlukan Program produk teknologi yang di desiminasikan ke Masyarakat berupa MEJIRUNG (Mesin Jeruji Sangkar Burung).

Berikut adalah beberapa potret kehidupan Buruh dan pengerajin pembuat jeruji sangkar burung, Penjual sangkar burung, dan Masyarakat di Jatiluhur Purwakarta Jawa Barat: 


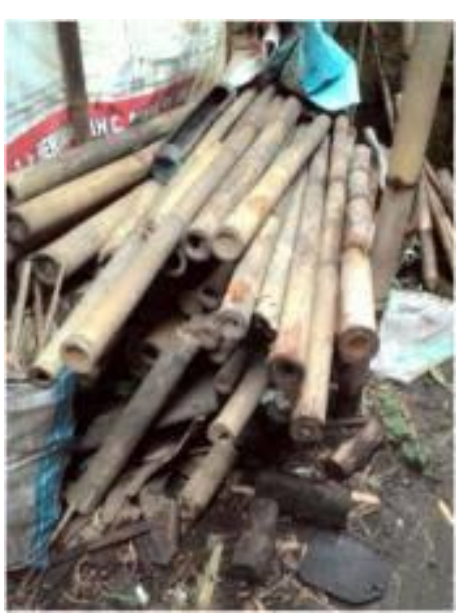

Gambar 1 Bahan Bambu untuk jeruji sangkar burung

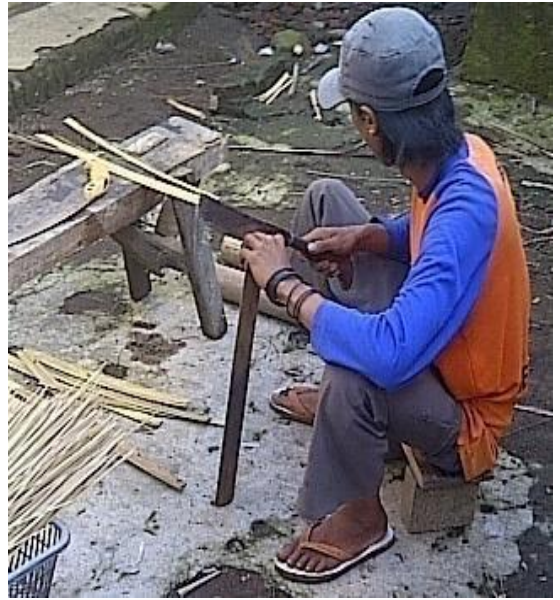

Gmabar 2 Membentuk dan membuat Jeruji sangkar burung dengan golok (Manual)

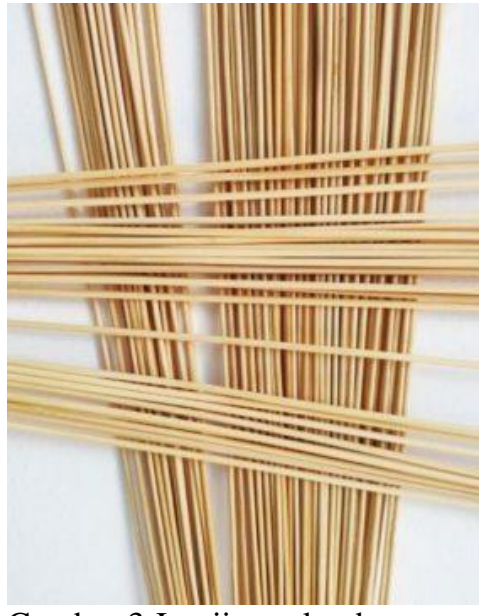

Gambar 3 Jeruji sangkar burung yang terbuat dari bahan bambu dan kayu

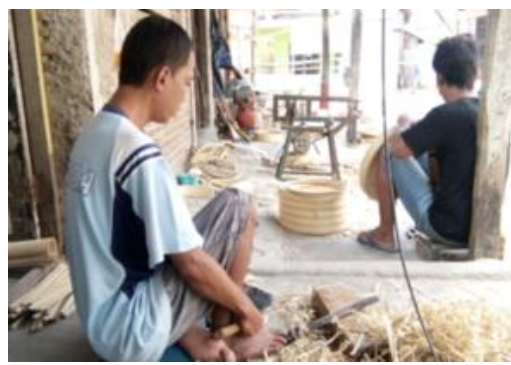

Gambar 4 Mengupas bambu dan membuat Jeruji sangkar burung dengan pisau (Konvensional)

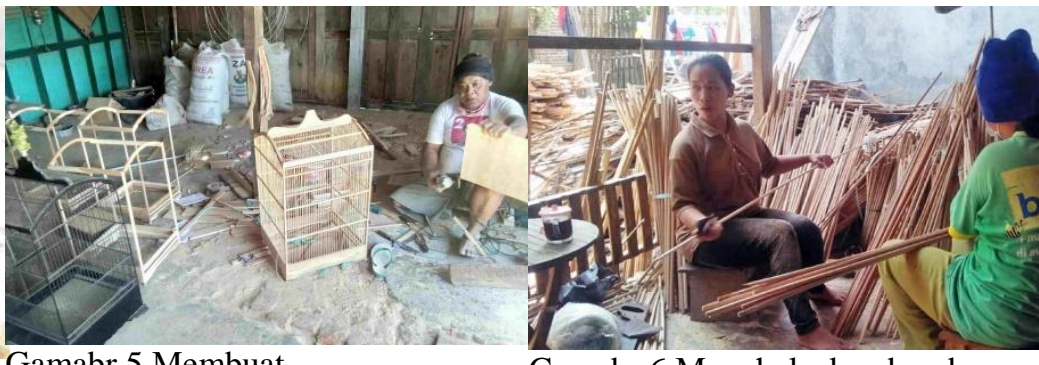

Gamabr 5 Membuat sangkar burung perpaduan kerangka sangkar dan jeruji sangkar burung
Gamabr 6 Menghaluskan bambu dan membuat Jeruji sangkar burung dengan amplas (Konvensional)

Dengan mengamati hal di atas dan survey maka munculah suatu ide untuk mendesiminasikan produk teknologi MEJIRUNG (Mesin Jeruji Sangkar Burung) agar dapat meringankan beban pengupasan dan pembentukan jeruji sangkar burung Buruh Pengupas dan pengrajin sangkar burung, penjual serta Masyarakat di Desa Jatimekar dan Mekargalih, Kecamatan Jatiluhur pada khususnya dan di Purwakarta, Jawa Barat pada umumnya.

Tujuan utama program produk teknologi yang di desiminasikan ke masyarakat ini adalah khalayak sasaran mampu meningkatkan kesejahteraan ekonomi, kemandirian dan produktif melalui penggunaan MEJIRUNG untuk pekerjaan membuat jeruji sangkar burung Selain itu, adanya sosialisasi dan desimanasi produk teknologi MEJIRUNG, seminar penggunaan teknologi MEJIRUNG ke buruh pembuat sangkar burung, masyarakat dan pelaku UMKM Mebeller. 


\section{METODE}

Metode dan langkah Program produk teknologi yang di desiminasikan ke Masyarakat

\begin{tabular}{|c|c|c|c|}
\hline $\begin{array}{c}\text { Persiapan } \\
\text { Desiminasi } \\
\text { Teknologi }\end{array}$ & $\begin{array}{c}\text { Pelaksanaan } \\
\text { Desiminasi } \\
\text { Teknologi }\end{array}$ & $\begin{array}{c}\text { Output/ } \\
\text { Hasil }\end{array}$ & Tujuan Akhir \\
\hline $\begin{array}{l}\text { Persiapan ini dilakukan } \\
\text { melalui survei lokasi } \\
\text { mitra terebih dahulu } \\
\text { agar program } \\
\text { desiminasi tepat sasaran } \\
\text { dan berhasil. Selain itu, } \\
\text { agar program ini dapat } \\
\text { dilaksanakan dengan } \\
\text { lancar, maka sebelum } \\
\text { semua aktifitas dimulai } \\
\text { terlebih dahulu } \\
\text { dilakukan sosialisasi } \\
\text { terhadap pihak-pihak } \\
\text { terkait, diantaranya } \\
\text { pemerintah daerah, } \\
\text { perangkat desa dan } \\
\text { gabungan Kelompok } \\
\text { pengrajin sangkar } \\
\text { burung, Buruh } \\
\text { pembentuk dan } \\
\text { pembuat jeruji sangkar } \\
\text { burung, dan pelaku } \\
\text { UMKM Mebeller, } \\
\text { Penjual sangkar burung, } \\
\text { perangkat desa serta } \\
\text { Masyarakat Desa } \\
\text { Jatimekar dan } \\
\text { Mekargalih, Kecamatan } \\
\text { Jatiluhur Kabupaten } \\
\text { Purwakarta yang }\end{array}$ & $\begin{array}{l}\text { Didesiminasikannya } \\
\text { produk yang telah } \\
\text { kami buat ke } \\
\text { masyarakat Cikedung } \\
\text { melalui Diklat } \\
\text { tentang keterampilan } \\
\text { penggunaan, } \\
\text { perawatan dan } \\
\text { pemanfaatan produk } \\
\text { teknologi } \\
\text { MEJIRUNG untuk } \\
\text { Membantu Kelompok } \\
\text { pengrajin sangkar } \\
\text { burung, Buruh } \\
\text { pembentuk dan } \\
\text { pembuat jeruji } \\
\text { sangkar burung, dan } \\
\text { pelaku UMKM } \\
\text { Mebeller, Penjual } \\
\text { sangkar burung, } \\
\text { perangkat desa serta } \\
\text { Masyarakat Desa } \\
\text { Jatimekar dan } \\
\text { Mekargalih, } \\
\text { Kecamatan Jatiluhur } \\
\text { Kabupaten } \\
\text { Purwakarta }\end{array}$ & $\begin{array}{l}\text { Peningkatan } \\
\text { Pengetahuan dan } \\
\text { keterampilan } \\
\text { untuk membuat } \\
\text { dan membentuk } \\
\text { bambu menjadi } \\
\text { jeruji sangkar } \\
\text { burung yang } \\
\text { produknya mejadi } \\
\text { produk bernilai } \\
\text { jual tinggi }\end{array}$ & $\begin{array}{l}\text { Kesejateraan } \\
\text { Sosial dan } \\
\text { ekonomi } \\
\text { Kelompok } \\
\text { pengrajin } \\
\text { sangkar burung, } \\
\text { Buruh } \\
\text { pembentuk dan } \\
\text { pembuat jeruji } \\
\text { sangkar burung, } \\
\text { dan pelaku } \\
\text { UMKM } \\
\text { Mebeller, } \\
\text { Penjual sangkar } \\
\text { burung, } \\
\text { perangkat desa } \\
\text { serta } \\
\text { Masyarakat } \\
\text { Desa Jatimekar } \\
\text { dan Mekargalih, } \\
\text { Kecamatan } \\
\text { Jatiluhur } \\
\text { Kabupaten } \\
\text { Purwakarta }\end{array}$ \\
\hline
\end{tabular}

menjadi wilayah

pelaksanaan program.

\section{Metode Kegiatan}

1. Sosialisasi Program produk teknologi yang di desiminasikan ke masyarakat Kelompok pengrajin sangkar burung, Buruh pembentuk dan pembuat jeruji sangkar burung, dan pelkau UMKM Mebeller, Penjual sangkar burung, perangkat desa serta Masyarakat Desa Jatimekar dan Mekargalih, Kecamatan Jatiluhur Kabupaten Purwakarta.

2. Mendemokan, penyerahan Mesin MEJIRUNG dan mengaplikasikan MEJIRUNG ke Kelompok pengrajin sangkar burung, Buruh pembentuk dan pembuat jeruji sangkar burung, dan pelaku UMKM Mebeller, Penjual sangkar burung, perangkat desa serta Masyarakat Desa Jatimekar dan Mekargalih, Kecamatan Jatiluhur Kabupaten Purwakarta

3. Evaluasi program produk teknologi yang di desiminasikan ke masyarakat tentang Mesin MEJIRUNG, evaluasi meliputi Kehandalan alat, kekuatan MEJIRUNG, dan Efektifitas alat MEJIRUNG

4. Evaluasi dilakukan setiap 2 bulan sekali selama program dan setelah program. 


\section{HASIL DAN PEMBAHASAN}

Hasil pengabdian terdiri dari Program Produk Teknologi yang di Desiminasikan ke Masyarakat (PTDM) berupa MEJIRUNG pada gabungan Kelompok pengrajin sangkar burung, Buruh pembentuk dan pembuat jeruji sangkar burung, dan pelaku UMKM Mebeller, Penjual sangkar burung, perangkat desa serta Masyarakat Desa Jatimekar dan Mekargalih, Kecamatan Jatiluhur Kabupaten Purwakarta, Jawa Barat adalah sebagai berikut:

1. Adanya Edukasi Teknologi bagi masyarakat mitra yang mengedepankan Sikap Pro-Kesahatan dan Pro-Lingkungan bagi gabungan Kelompok pengrajin sangkar burung, Buruh pembentuk dan pembuat jeruji sangkar burung, dan pelaku UMKM Mebeller, Penjual sangkar burung, perangkat desa serta Masyarakat Desa Jatimekar dan Mekargalih, Kecamatan Jatiluhur Kabupaten Purwakarta, Karena penggunaan MEJIRUNG yang aman dari kesehatan.

2. Dengan adanya Program produk teknologi yang di desiminasikan ke masyarakat ini maka kelompok sasaran atau mitra mempunyai pengetahuan, keahlian serta mampu memanfaatkan produk teknologi MEJIRUNG yang bisa dipakai untuk membuat dan membentuk jeruji sangkar burung yang mana alat MEJIRUNG ini mudah dalam pengoperasian, aman dalam menggunakan dan efektif dalam membuat jeruji sangkar burung.

3. Adanya kolaborasi antara masyarakat Desa Jatimekar dan Mekargalih, Purwakarta, Jawa Barat dengan Peneliti/Dosen Universitas Singaperbangsa Karawang dalam mendesiminasikan dan pengembangan teknologi MEJIRUNG yang bisa membantu buruh Kelompok pengrajin sangkar burung, Buruh pembentuk dan pembuat jeruji sangkar burung, dan pelaku UMKM Mebeller, Penjual sangkar burung, perangkat desa serta Masyarakat Desa Jatimekar dan Mekargalih, Kecamatan Jatiluhur Kabupaten Purwakarta, dan masyarakat sekitar.

4. Adanya pemahaman produk teknologi MEJIRUNG melalui desiminasi, pelatihan penggunaan, dan perawatan produk mesin jeruji sangkar burung (MEJIRUNG).

5. Adanya pelaksanaan program produk teknologi MEJIRUNG ini ternyata dapat meningkatkan Skill teknologi dan semakin memperkuat usaha gabungan Kelompok pengrajin sangkar burung, Buruh pembentuk dan pembuat jeruji sangkar burung, dan pelaku UMKM Mebeller, Penjual sangkar burung, perangkat desa serta Masyarakat Desa Jatimekar dan Mekargalih, Kecamatan Jatiluhur Kabupaten Purwakarta yang selama ini telah menjadi bidang usahanya .

6. Setelah program desiminasi produk teknologi MEJIRUNG maka ada kegiatan Penyerahan mesin jeruji sangkar burung (MEJIRUNG) yang telah di buat sebanyak 10 buah alat ke Kelompok pengrajin sangkar burung, Buruh pembentuk dan pembuat jeruji sangkar burung, dan pelaku UMKM Mebeller, Penjual sangkar burung, perangkat desa serta Masyarakat Desa Jatimekar dan Mekargalih, Kecamatan Jatiluhur Kabupaten Purwakarta

\section{Proses Kegiatan Pengabdian Kepada Masyarakat MEJIRUNG}

Proses Kegiatan Pengabdian Kepada Masyarakat MEJIRUNG terdiri dari Persiapan Pelaksanaan Program Produk Teknologi yang di Desiminasikan ke Masyarakat, Pelaksanaan kegiatan dan Evaluasi dan Tahapan Pencapian dan Keberlanjutan Program Produk Teknologi yang di Desiminasikan ke Masyarakat. 


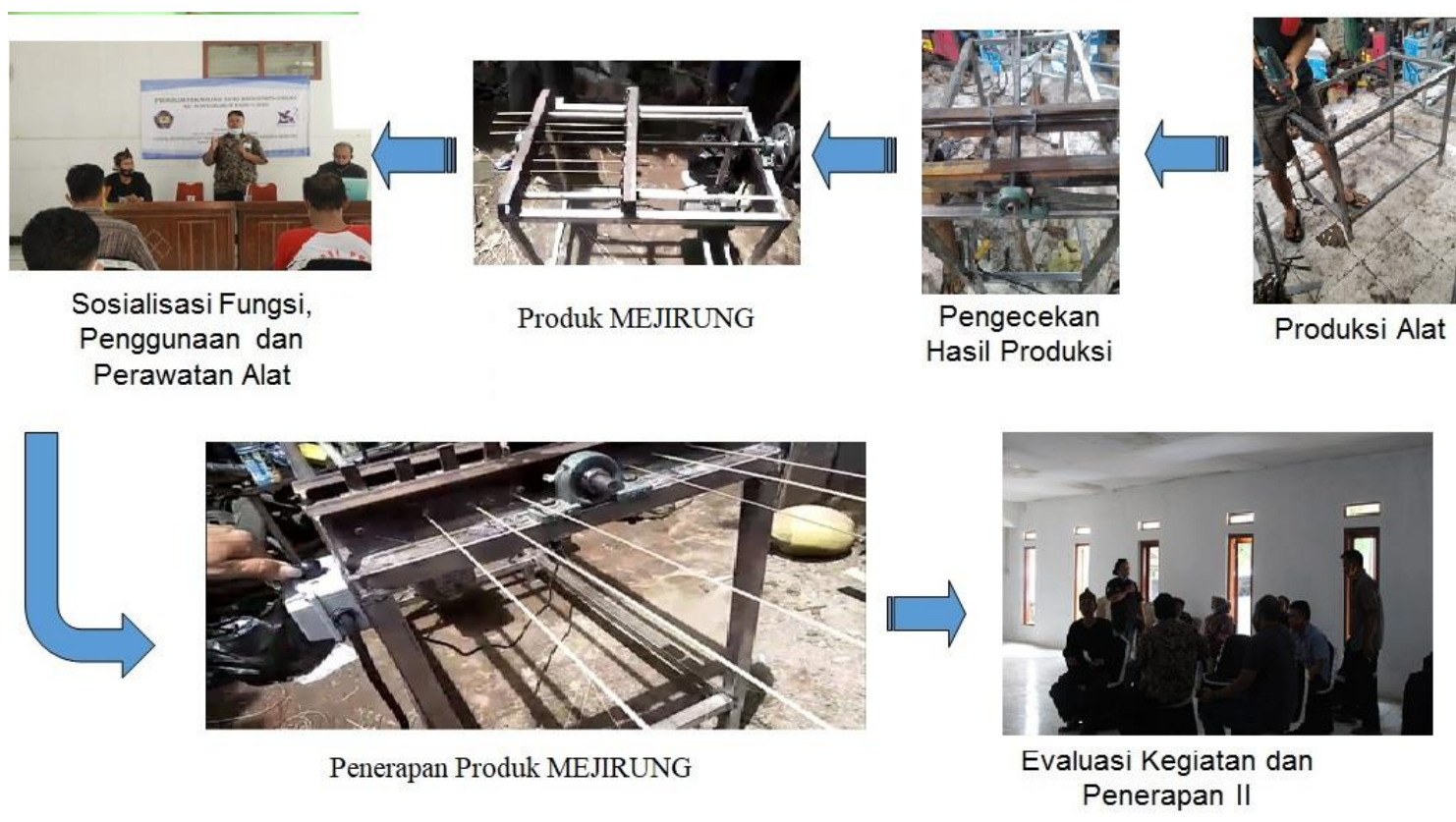

Gambar 7. Proses Kegiatan Pengabdian Kepada Masyarakat MEJIRUNG

\section{Persiapan Pelaksanaan Program Produk Teknologi yang di Desiminasikan ke Masyarakat}

Agar program ini dapat dilaksanakan dengan lancar, maka sebelum semua aktifitas dimulai terlebih dahulu dilakukan sosialisasi terhadap pihak-pihak terkait, diantaranya pemerintah daerah, dan Kelompok pengrajin sangkar burung, Buruh pembentuk dan pembuat jeruji sangkar burung, dan pelaku UMKM Mebeller, Penjual sangkar burung, perangkat desa serta Masyarakat Desa Jatimekar dan Mekargalih, Kecamatan Jatiluhur Kabupaten Purwakarta, yang menjadi wilayah pelaksnaaan Program produk teknologi MEJIRUNG yang di desiminasikan ke Masyarakat. Dengan adanya sosialisasi ini diharapkan semua pihak terkait mendukung sepenuhnya program ini baik secara kelembagaan, materiil maupun moril.

\section{Tahapan Pelaksanaan}

Untuk memberikan solusi terhadap permasalahan-permasalahan mitra, maka tahapan Program produk teknologi MEJIRUNG yang di desiminasikan ke Masyarakat disusun sebagai berikut :

\begin{tabular}{|c|c|}
\hline Kegiatan & Luaran \\
\hline $\begin{array}{l}\text { Program produk } \\
\text { teknologi MEJIRUNG } \\
\text { yang di desiminasikan } \\
\text { ke Masyarakat melalui } \\
\text { seminar dan pelatihan }\end{array}$ & $\begin{array}{l}\text { 1. Kebermanfaatan pada Kemampuan kelompok sasaran } \\
\text { meningkat } 90 \% \text { dalam pemanfaan produk teknologi MEJIRUNG } \\
\text { 2. Peserta mampu mengoperasikan dan merawat MEJIRUNG } \\
\text { 3. Perserta mampu mengembangkan Produk teknologi alat } \\
\text { MEJIRUNG dengan lebih kreatif dan lebih diminati pasar }\end{array}$ \\
\hline $\begin{array}{l}\text { Melakukan } \\
\text { Pendampingan }\end{array}$ & $\begin{array}{l}\text { 1. Mampu menemukan, menganalisis dan memberikan solusi } \\
\text { terhadap masalah-masalah yang mungkin } \\
\text { muncul dalam menjalankan Program Produk Teknologi MEJIRUNG } \\
\text { yang di Desiminasikan ke Masyarakat } \\
\text { 2. Mampu memberikan masukan-masukan untuk pengembangan } \\
\text { produk teknologi pada program diseminasi }\end{array}$ \\
\hline $\begin{array}{l}\text { Pelaporan dan } \\
\text { Publikasi }\end{array}$ & $\begin{array}{l}\text { 1. Laporan kegiatan } \\
\text { 2. Artikel yang dipublikasikan }\end{array}$ \\
\hline
\end{tabular}




\section{Evaluasi dan Tahapan Pencapian dan Keberlanjutan Program Produk Teknologi yang di Desiminasikan ke Masyarakat}

Setiap proses pembelajaran setelah sudah selesai dilaksanakan secara keseluruhan maka dilakukan evaluasi sebagai acuan feedback untuk menjamin keberlangsungan kemitraan (Eman Suherman, 2008: 120)

\begin{tabular}{|c|c|c|c|}
\hline \multicolumn{4}{|c|}{ Capaian } \\
\hline Tahap I & Tahap II & Tahap III & Tahap IV \\
\hline $\begin{array}{l}\text { Anggota Kelompok } \\
\text { pengrajin sangkar } \\
\text { burung, Buruh } \\
\text { pembentuk dan } \\
\text { pembuat jeruji } \\
\text { sangkar burung, dan } \\
\text { pelaku UMKM } \\
\text { Mebeller, Penjual } \\
\text { sangkar burung, } \\
\text { perangkat desa serta } \\
\text { Masyarakat mampu } \\
\text { cara } \\
\text { mengoperasikan, dan } \\
\text { perawatan produk } \\
\text { teknologi } \\
\text { MEJIRUNG agar } \\
\text { meringankan } \\
\text { pekerjaan dalam } \\
\text { membuat jeruji } \\
\text { sangkar burung yang } \\
\text { aman, efektif dan } \\
\text { efisien. }\end{array}$ & $\begin{array}{l}\text { Partisipasi anggota } \\
\text { mitra, dalam } \\
\text { produk teknologi } \\
\text { MEJIRUNG yang } \\
\text { di desiminasikan ke } \\
\text { Masyarakat mitra } \\
\text { sehingga usaha } \\
\text { diseminasi produk } \\
\text { teknologi berjalan } \\
\text { lancar }\end{array}$ & $\begin{array}{l}\text { Setiap Anggota } \\
\text { mitra mau mengajak } \\
\text { anggota keluaraga } \\
\text { atau orang terdekat } \\
\text { untuk terlibat dalam } \\
\text { proses Program } \\
\text { produk teknologi } \\
\text { MEJIRUNG yang di } \\
\text { desiminasikan ke } \\
\text { Masyarakat } \\
\text { (Kelompok pengrajin } \\
\text { sangkar burung, Buruh } \\
\text { pembentuk dan } \\
\text { pembuat jeruji sangkar } \\
\text { burung, dan pelaku } \\
\text { UMKM Mebeller, } \\
\text { Penjual sangkar } \\
\text { burung, perangkat } \\
\text { desa serta Masyarakat } \\
\text { Desa Jatimekar dan } \\
\text { Mekargalih, } \\
\text { Kecamatan Jatiluhur } \\
\text { Kabupaten } \\
\text { Purwakarta }\end{array}$ & $\begin{array}{l}\text { Meningkatnya } \\
\text { kesejahteraan dan } \\
\text { pendapatan ekonomi } \\
\text { anggota,keluarga } \\
\text { maupun tetangga } \\
\text { terdekat Kelompok } \\
\text { pengrajin sangkar } \\
\text { burung, Buruh } \\
\text { pembentuk dan pembuat } \\
\text { jeruji sangkar burung, } \\
\text { dan pelaku UMKM } \\
\text { Mebeller, Penjual } \\
\text { sangkar burung, } \\
\text { perangkat desa serta } \\
\text { Masyarakat Desa } \\
\text { Jatimekar dan } \\
\text { Mekargalih, Kecamatan } \\
\text { Jatiluhur Kabupaten } \\
\text { Purwakarta, melalui } \\
\text { Program produk } \\
\text { teknologi MEJIRUNG } \\
\text { yang di desiminasikan } \\
\text { ke Masyarakat. }\end{array}$ \\
\hline
\end{tabular}

Dari Hasil pelaksanaan PTDM produk teknologi alat MEJIRUNG di Desa Jatimekar dan Mekargalih, Kecamatan Jatiluhur Kabupaten Purwakarta, Jawa Barat ini ternyata mampu memberikan kontribusi terhadap sektor lain misalnya, pertanian, kesehatan, dan Manajemen teknologi. Dibidang industri kreatif dan kerjainan, MEJIRUNG mampu memberikan kontribusi positif yaitu membuat jeruji sangkar burung, yang mana mudah dalam pengoperasian, aman dalam menggunakan dan efektif dalam membuat jeruji sangkar burung.

Selanjutnya, MEJIRUNG memberikan kontribusi dibidang kesehatan pada gabungan Kelompok pengrajin sangkar burung, Buruh pembentuk dan pembuat jeruji sangkar burung, dan pelaku UMKM Mebeller, Penjual sangkar burung, perangkat desa serta Masyarakat Desa Jatimekar dan Mekargalih, Kecamatan Jatiluhur Kabupaten Purwakarta, karena mereka mengandalkan alat MEJIRUNG untuk membuat jeruji sangkar burung. Buruh pembuat jeruji sangkar burung yang membuat jeruji sangkar burung tanpa adanya alat MEJIRUNG untuk mebantu pekerjaannya maka akan terasa berat dan lama akan proses pembuatan jeruji sangkar burung serta lama kelamaan bisa mengakibatkan cidera maupun kebungkukan pada tulang tangan dan belakang.

Selain itu, MEJIRUNG memberikan kontribusi juga dibidang Manajemen teknologi. Hal ini bisa dilihat dari kemampuan pemanfaatan produk teknologi kelompok sasaran atau mitra meningkat $90 \%$ dalam bidang pembuatan jeruji sangkar burung. Selanjutnya gabungan Kelompok pengrajin sangkar burung, Buruh pembentuk dan pembuat jeruji sangkar burung, dan pelaku UMKM Mebeller, Penjual sangkar burung, perangkat desa serta Masyarakat, juga meningkat dalam Kemampuan Sumber Daya Manausia (SDM) kelompok sasaran atau mitra 
meningkat $80 \%$ dalam bidang manajemen teknologi. Selain itu, kemampuan kelompok sasaran juga meningkat $70 \%$ dalam perawatan MEJIRUNG .

\section{SIMPULAN}

Dari kegiatan Program Produk Teknologi yang di Desiminasikan ke Masyarakat (PTDM) ini tentang Alat MEJIRUNG (Mesin Jeruji Sangkar Burung) Untuk Meningkatkan Kinerja dan ekonomi gabungan Kelompok pengrajin sangkar burung, Buruh pembentuk dan pembuat jeruji sangkar burung, dan pelaku UMKM Mebeller, Penjual sangkar burung, perangkat desa dan warga di Kecamatan Jatiluhur Kabupaten Purwakarta, Jawa Barat dapat disimpulkan bahwa :

Warga khususnya buruh dan pelakau UMKM Pembuat jeruji sangkar burung dapat mengetahui dengan baik pemanfaatan dan perawatan MEJIRUNG Untuk Memudahkan Pekerjaan pembuatan jeruji sangkar burung dan meningkatkan kinerja dan ekonomi gabungan Kelompok pengrajin sangkar burung, Buruh pembentuk dan pembuat jeruji sangkar burung, dan pelaku UMKM Mebeller, Penjual sangkar burung, perangkat desa dan warga di Kecamatan Jatiluhur Kabupaten Purwakarta,

Selain itu, gabungan Kelompok pengrajin sangkar burung, Buruh pembentuk dan pembuat jeruji sangkar burung, dan pelaku UMKM Mebeller, Penjual sangkar burung, perangkat desa dan warga dapat mengetahui cara penggunaan atau memposisikan dan perawatan MEJIRUNG yang baik dan benar agar terjaga kualitas atau tidak mengalami kerusakan pada alat MEJIRUNG.

Perlu kegiatan evaluasi lanjutan tentang optimalisasi pemanfaatan teknologi MEJIRUNG untuk Kelompok pengrajin sangkar burung, Buruh pembentuk dan pembuat jeruji sangkar burung, dan pelaku UMKM Mebeller, Penjual sangkar burung, perangkat desa dan warga masyarakat

\section{SARAN}

1. Perlu dukungan berbagai pihak untuk pengaplikasian MEJIRUNG

2. Proses pengerjaan program produk teknologi yang di desiminasikan ke masyarakat ini tentang MEJIRUNG dilakukan dengan membuat tim inti di lokasi

3. Program produk teknologi yang di desiminasikan ke masyarakat ini tentang MEJIRUNG ini harus memberdayakan masyarakat sekitar dalam proses pengaplikasian

\section{UCAPAN TERIMA KASIH}

Kami mengucapkan Terimakasih atas dukungan pendanaan Program produk teknologi yang di desiminasikan ke masyarakat Tahun 2020 Kepada Direktorat Riset dan Pengabdian Masyarakat (DRPM), Direktorat Jendral Penguatan Riset dan Pengembangan dari Kementerian Riset Dan Teknologi/ Badan Riset Dan Inovasi Nasional.

\section{DAFTAR PUSTAKA}

Badan Pusat Statistik (BPS) Kabupaten Purwakarta. 2019. Kabupaten Purwakarta dalam Angka. Purwakarta: BPS Kabupaten Purwakarta.

Suherman Eman, 2008: Desain Pembelajaran Kewirausahaan, Alfabeta Bandung 